EPiC Series in Engineering
Volume 3, 2018, Pages 302-309
HIC 2018. 13th International
Conference on Hydroinformatics

\title{
Optimal design of water pipeline and micro- hydro turbine by genetic algorithm
}

\author{
Camillo Bosco ${ }^{1}$, Giuseppe Pezzinga1, Marco Sinagra ${ }^{2}$, Tullio Tucciarelli ${ }^{2}$ \\ ${ }^{1}$ Dept. of Civil Engineering and Architecture, Università degli Studi di Catania, Via Santa Sofia \\ 64, 95123 Catania Italy. \\ ${ }^{2}$ Dept. of Civil, Environmental, Aerospace, Material Engineering, Università degli Studi di \\ Palermo, Viale delle Scienze, 90128 Palermo, Italy. \\ camillo.bosco914@gmail.com
}

\begin{abstract}
The economic value of the potential energy hidden in water resources is becoming more and more relevant for pipe design. In this work a new way to design drinking main waterlines, embedding also the potential hydroelectric production as pipeline benefit, is presented. The optimum design of a cross-flow turbine, on the basis of the available head jump and discharge is first outlined; the description of a genetic algorithm to minimize the total cost (pipeline plus machinery) minus the net benefit (hydropower production) is then presented. Finally, a comparison is carried out among the costs of a case study pipeline assuming a) no hydropower production and traditional design criteria and b) two different scenarios with different values of benefits per unit energy production. The two scenarios lead to hydropower production with constant impeller rotational velocity in one case and with variable impeller rotational velocity in the other one.
\end{abstract}

\section{Introduction}

Water pipelines have been traditionally designed according to the minimum construction cost, for assigned hydraulic constraints. This was equivalent to maximize the hydraulic power dissipation, and was justified by the low economic value of the potential energy, which was almost negligible in the past, up to the present times. The new energy production/consumption strategy, based on the development of a distributed smart grid where almost all the nodes are simultaneously sink and source nodes, gives today a distinguished value to the hydropower production, especially for water management companies, that have in other sites large energy consumptions for water pumping and treatment. Moreover, the large variability of the discharge inside the pipes leads to the need of guaranteeing an upper boundary head dissipation for the peak discharge by using a diameter size which results oversized in a large part of the year, when the excess energy can be used for a significant hydropower production. Because the energy loss along the pipe is almost proportional to the inverse of 
the fifth power of the diameter, their installation is much more convenient during the construction of the new ones, because it is possible, with a small additional cost, to avoid the dissipation of large part of the available potential energy. Starting from this point, a new design method for new aqueducts is proposed to identify the best configuration among the many possible ones. Decision variables are the pipeline diameter, the outer diameter of the turbine, the eventual allocation of a by-pass to limit the turbined discharge, as well as the possible impeller rotational velocity control.

\section{Material and methods}

The idea of installing micro-hydro plants in aqueducts is not new. Actually, for more than 30 years waterworks agencies have been installing small hydropower plants into water distribution systems as a source of additional revenue, always considering that the availability of adequate head and flow is the primary requirement in a water supply system [1]. In 1990 Afshar et al. [2] investigated the possibility to maximize the net benefit (i.e. benefit minus cost) of the system made of main transmission pipeline and related mini-hydro plants while satisfying the water demand and the minimum permissible pressure head. Specifically, Afshar et al. [2] developed a dynamic algorithm to optimize the design of a transmission line in water supply systems, considering the possibility to install some turbines along the pipeline. Their dynamic programming (DP) model was developed with the objective of determining the optimum capacities of the turbines to be used and the optimum diameters of the pipeline. Pezzinga and Tosto [3] analyzed the possibility of taking advantage of the surplus of energy in a system of main waterlines by an iteratively linearized optimization model.

Considering recent technologies, Fontana et al. [4] investigated the convenience to install a minihydro plant in water supply systems instead of using only PRVs with interesting results in terms of economical advantages. Nowadays, an effective choice for exploiting water energy in water distribution system, in terms of the type of turbine, could be obtained by installing a cross-flow turbine [5], with a Cink shaped semicircular segment, presenting high performances in typical discharge and head ranges of water supply system (Figure 1).
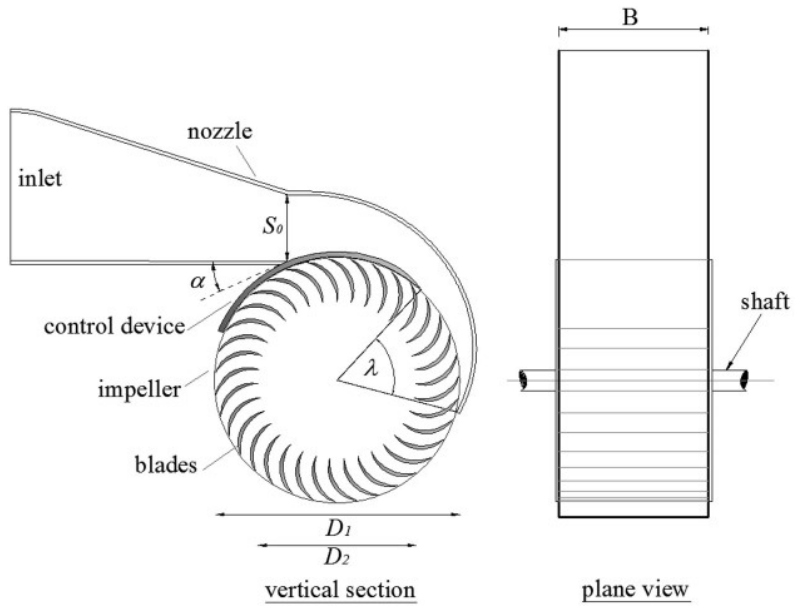

Figure 1: Vertical section and a plane view of the cross-flow turbine with the Cink control device.

Cink segment is quite important because it allows to maintain the same head jump with different discharge values by regulating its position inside the turbine case, with a minimum efficiency reduction. 


\subsection{Electronic regulation}

Concerning the mentioned type of turbine, Sinagra et al. [6] validated the following semi-empirical formula by lab experiments to relate the net hydraulic head with the mean particle velocity at the impeller inlet:

$$
V=C_{v} \sqrt{2 g\left(H-\frac{\omega^{2} R^{2}}{2 g}\right)}
$$

where $H$ is the available head at the turbine, $\omega$ is the impeller rotational velocity, $R$ is the outer radius of the impeller and $C_{v}$ is a velocity coefficient, a bit smaller than one.

In the case of negligible energy losses along the turbine supply pipe, or when the discharge variation is small enough to provide an almost constant head jump, the hydraulic regulation given by Cink segment is able to guarantee a constant inlet velocity inside the turbine impeller during discharge variations. This implies the possibility of keeping the velocity ratio, given by the ratio between the inlet particle velocity and the velocity of the rotating system in the same point, at the optimal design value. This value is almost 2 for open air outflow turbines and ranges between 1.7 and 2.4 in the case of pressurized outflow [7], so in our case the regulation system should allow to preserve the following relationship, where $\alpha$ is the angle attack at the inlet of the impeller.

$$
V_{o p t}=\frac{\omega D}{\cos \alpha}
$$

When the pipeline diameters are the result of a traditional design, neglecting the potential water energy value, the strong head jump variations lead to significant variation of the particle inlet velocities. In this case the only way to maintain the optimality of the velocity ratio is to change accordingly the impeller rotational velocity. This implies the use of inverters, that have an additional cost and increase the complexity of the system [8]. On the other hand, this gives the possibility of maintaining always optimal efficiency for very variable discharges, as it often happens in water supply systems. The desirable impeller velocity can be obtain by merging Eqs. (1) and (2).

$$
\omega=\frac{C_{v}}{R} \cos \alpha \sqrt{\frac{2 g H}{\left(4+C_{v}^{2} \cos ^{2} \alpha\right)}}
$$

Selecting the outer diameter as the optimal one through the GA described in the following, crossflow turbine was designed according to the procedure described in the numerical study by Sammartano et al. (2015) [5]. Their analyses, highlighting that opening degree of Cink segment $\lambda$ and the velocity ratio $V_{r}$ are the main parameters which affect cross-flow turbine efficiency, led to a useful chart of turbine efficiency $\eta\left(\lambda, V_{r}\right)$ which could allow to estimate the produced energy (Figure 2 ).

In particular, higher values of angle $\lambda$ give higher efficiency values, so the possibility to design a by-pass to reduce the discharge variations at the inlet of the turbine in order to increase the average value of this angle will be also taken into account through the GA. 


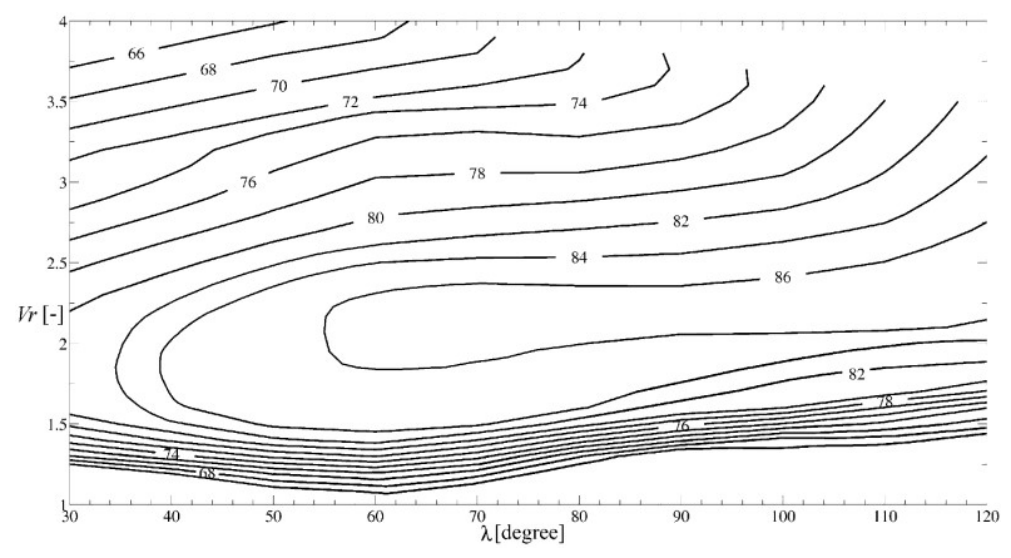

Figure 2: Efficiency curves $\eta=\eta\left(\lambda, V_{r}\right)$ for the cross-flow turbine.

\subsection{Developed GA}

As mentioned above, pipe diameter, outer turbine diameter, the convenience of installing an inverter and the possibility to by-pass a certain percentage of the maximum discharge are investigated through a GA, minimizing the difference between costs and benefits.

The total cost to be considered will be given by the costs of pipeline, and the plant costs, i.e. civil works, turbine, possible inverter, generator and power panel, and can be expressed by:

$C_{\text {tot }}=r\left(C_{\text {pipe }}+C_{\text {civil-works }}+C_{\text {turbine }}+C_{\text {gen }, p . p .}+C_{\text {inverter }}\right)$

In this expression the capital recovery factor $r$ was assumed equal to 0.05 . Specifically, costs related to excavation materials, estimated as $50 € / \mathrm{m}^{3}$, where computed by considering an excavation width equal to $0.8 \mathrm{~m}$ plus the pipe selected diameter and an average excavation depth of $2 \mathrm{~m}$. Conduct costs were estimated according to the document "Prezzario Regionale Sicilia 2013" for the selected type of conduct (Table 1).

\begin{tabular}{|l|c|l|c|l|c|}
\hline Diameter & Cost $[€ / \mathrm{m}]$ & Diameter & Cost $[€ / \mathrm{m}]$ & Diameter & Cost $[€ / \mathrm{m}]$ \\
\hline DN 300 & 137,1 & DN 400 & 205,7 & DN 500 & 280,3 \\
\hline DN 350 & 186,8 & DN 450 & 256,7 & DN 600 & 349,7 \\
\hline
\end{tabular}

Table 1: Unit costs of cast-iron conduct varying with commercial diameters considered in the case study.

Civil works costs related to the plant were considered constant and equal to $20.000 €$ and the other costs were obtained from market surveys, linking costs to nominal powers. Surveys concerning asynchronous motors with two pole pairs were considered, along with inverter costs that were doubled to take into account one single replacement during the investment time. Costs curves are shown in Figure 3. 


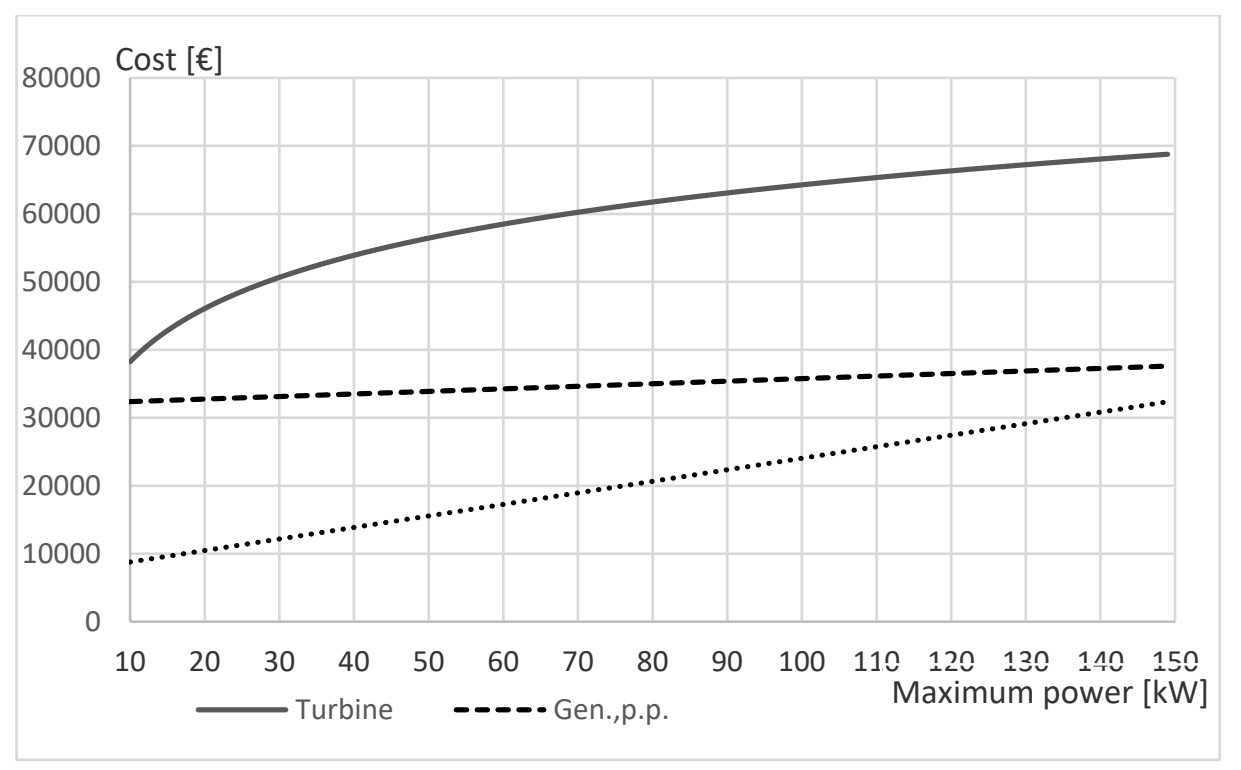

Figure 3: Cost curves of turbine, generator with power panel and inverter inferred from market surveys.

With regard to benefit $B$, both trading direct income and public incentives for renewable energy production can be considered. Given $b$, the total benefit per unit energy production, the following expression is used for $B$ estimation:

$$
B=b \sum_{i=1}^{12}\left[\eta_{i}\left(V_{r}, \lambda\right) \gamma Q_{i} H_{i} \Delta t_{i}\right]
$$

where $i$ is the generic month, $\eta$ is the total efficiency, $\gamma$ is the water weight per unit volume, $Q$ is the discharge and $\Delta t_{i}$ is the number of seconds per month.

The total efficiency, obtained through a linear interpolation of the chart of Figure 2, depends only on $V_{r}$ and $\lambda$ because generator and inverter efficiencies are considered constant, equal to 0,88 and 0,97 respectively. The solution was coded by 23 bits:

- 10 bits to investigate the optimal theoretical diameter pipe, searching from 1 to $1024 \mathrm{~mm}$;

- 9 bits to investigate the optimal outer turbine diameter, searching from 1 to $512 \mathrm{~mm}$;

- 1 bit to consider the installation or not of the inverter to vary impeller rotational velocity;

- 3 bits to design the by-pass device in terms of peak flow percentage to drive to the impeller inlet, searching from $30 \%$ to $100 \%$ with $10 \%$ steps.

The objective function was computed as the difference between the annual cost given by Eq. (4) and benefits given by Eq. (5) for 50 individuals through 1000 generations. Mutation and single-point crossover probability were calibrated empirically to the values of 0.1 and 0.01 respectively. The constraints of the optimization problem were enforced by increasing considerably the objective function values of beyond constrains solutions. Hence, solutions with negative available head and with unacceptable parameters concerning the designed cross-flow turbine were neglected. In particular, if the impeller width is lower than 3-4 cm the 2D hypothesis assumed by Sammartano et al. fails because the surface effects of the impeller plates become relevant. Furthermore structural problems arise if the impeller width is large several times the external diameter [5]. 


\section{Results and discussion}

The results were obtained from a case study that refers to the hydraulic conditions of a water supply system of a town in the southern part of Italy, which is characterized by topographical jump Y between the upstream and downstream tanks equal to $124 \mathrm{~m}$, pipeline length $\mathrm{L}$ equal to $10 \mathrm{~km}$ and monthly discharges reported in Table 2.

\begin{tabular}{|c|c|c|c|c|c|}
\hline Month & Flow $[1 / \mathrm{s}]$ & Month & Flow $[1 / \mathrm{s}]$ & Month & Flow $[1 / \mathrm{s}]$ \\
\hline January & 95 & May & 135 & September & 160 \\
\hline February & 98 & June & 185 & October & 115 \\
\hline March & 120 & July & 205 & November & 90 \\
\hline April & 135 & August & 220 & December & 115 \\
\hline
\end{tabular}

Table 2: Monthly discharge values for the analyzed case study.

The traditional method is first applied to the case study, without considering hydropower production. Specifically, the minimum cost pipeline is computed by considering steel and cast-iron pipes. Comparing the costs of both material, the minimum design cost is obtained with the cast-iron pipeline, assuming a Hazen-Williams roughness coefficient equal to 100 , theoretical inner pipeline diameter equal to $393.5 \mathrm{~mm}$, leading to a DN350 smaller diameter, extended for $1,3 \mathrm{~km}$, and a DN400 bigger diameter, extended for $8,7 \mathrm{~km}$.

The costs of the pipeline are 2.032.600 $€$ and costs related to excavated material are 1.193.500€, for a total amount of $3.226 .100 €$. Considering the capital recovery factor $r$ equal to 0.05 , the annual cost is equal to $161.305 €$.

Configurations with hydropower production were investigated by running the developed GA, so a mini-hydro plant was designed for each individual and generation and thus up to the last generation. In the end, the best combination of diameters, presence or not of inverter and optimal percentage of maximum discharge is obtained in terms of economical revenues.

The total benefit per unit energy $b$ in Italy is now equal to $0,21 €$ per each $\mathrm{kWh}$ produced by hydroplants under $250 \mathrm{~kW}$, for 20 years after the installation (scenario 'A'). Nevertheless, values of $b$ could decrease in the future, so a benefit equal to $0,10 € / \mathrm{kWh}$ was considered (scenario 'B').

The two scenarios are characterized by different solutions related to the same case study. If lower values of $b$ are adopted, the optimal solution changes, with a diameter reduction and the presence of the inverter. In the following Table 3, the optimal values of GA decision variables are shown with relative costs and benefits. 


\begin{tabular}{|l|c|c|c|c|}
\hline \multicolumn{5}{|c|}{ Decision variables for the optimal individuals in both hydropower production scenarios } \\
\hline Sc. & Pipeline diameter $[\mathrm{mm}]$ & Turbine diameter $[\mathrm{mm}]$ & Inverter [Yes $\backslash$ No] & Peak flow [\%] \\
\hline A & 504 & 230 & No & 100 \\
\hline B & 416 & 249 & Yes & 100 \\
\hline \multicolumn{5}{|c|}{ Economical values for the optimal individuals in both hydropower production scenarios } \\
\hline Sc. & Total cost $[€]$ & Annual cost $[€]$ & Annual return $[€]$ & Annual net $[€]$ \\
\hline A & 4.260 .400 & 213.020 & 193.654 & 19.366 \\
\hline B & 3.575 .040 & 178.752 & 63.163 & 115.588 \\
\hline
\end{tabular}

Table 3: Optimal decision variables and relative economical values in A and B scenarios.

It is worth to notice that optimal theoretical pipeline diameter and total costs grow by increasing the benefit per unit energy $b$ because this growth justifies higher values of available head, strictly related to produced power, at the inlet of the impeller. For this reason, the annual return of scenario ' $\mathrm{A}$ ' with $b$ equal to $0,21 € / \mathrm{kWh}$ is higher than the triple of scenario 'B', with b equal to $0,10 € / \mathrm{kWh}$. The absence of the inverter in scenario ' $A$ ' is due to the strong reduction of head variability [8], so only in scenario ' $\mathrm{B}$ ', where the residual heads are still quite fluctuating, it is preferable to install an inverter. Moreover, installing a by-pass in both scenarios of the case study is not convenient because the beneficial effects on plant costs and produced power provided with reducing the maximum turbined discharge, given by increasing the $\lambda$ average value and getting higher efficiencies, are lower than the ones provided by the production of the lost discharge.

In the histograms of Figure 4 the comparison of monthly total efficiencies, available head, impeller rotational velocity and produced electrical power are shown for the two scenarios.

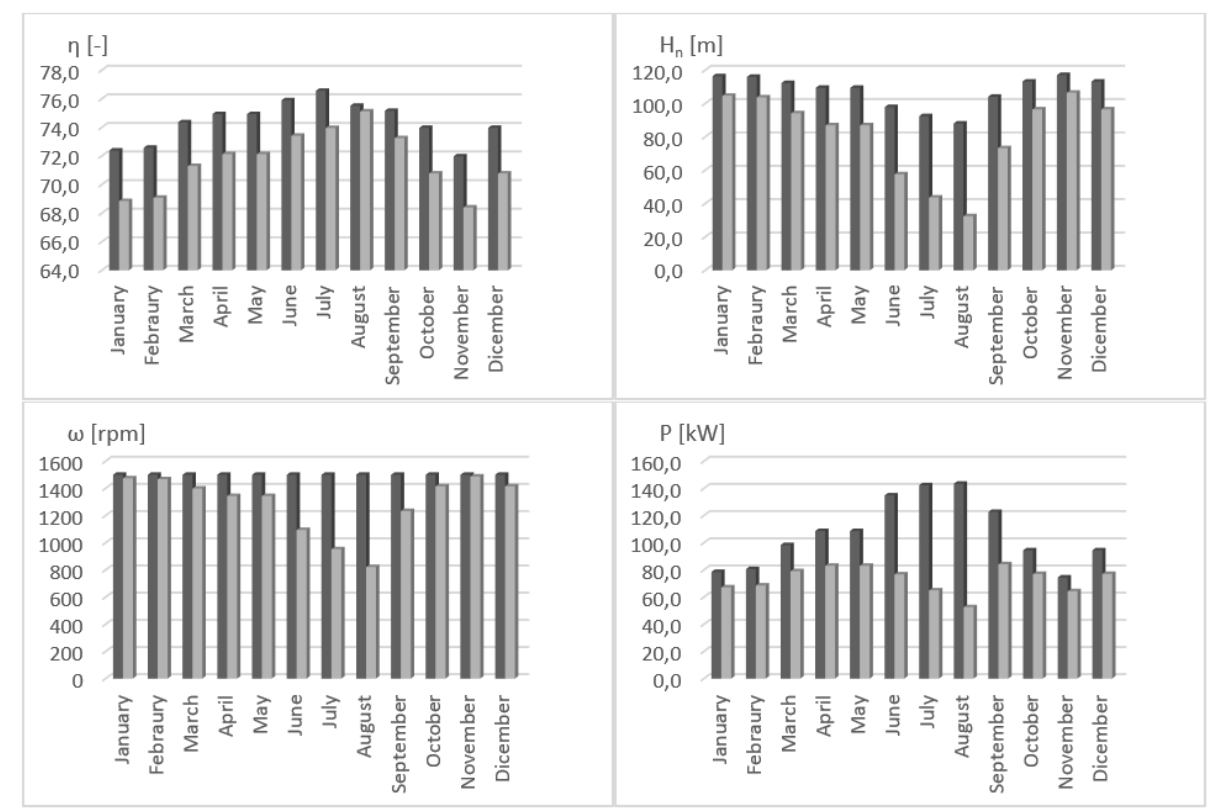

Figure 4: Monthly parameters values for the solutions in scenarios A (dark grey) and B (light grey). 
It is worth to notice that efficiencies are higher in scenario ' $A$ ' despite the missing use of an inverter and monthly velocity ratios $V_{r}$ are not always equal to the optimal value. The reason is due to the additional inverter efficiency and to the fact that the average of monthly opening degrees $\lambda$ in scenario ' $B$ ' is quite lower because of the higher head and related inlet velocity variability. Indeed, variations on opening degrees $\lambda$ are useful to regulate the inlet area which is inversely proportional to the velocity; therefore stronger monthly inlet velocity variations lead to stronger $\lambda$ reduction from its maximum design value. Nevertheless efficiencies in scenario ' $B$ ' do not drop down considerably because the inverter sets the impeller rotational velocity $\omega$ to values given by Eq. (3). Finally, in scenario 'B' the smaller pipe diameter lead to higher available head variability, implying the remarkable effect on power values, following different trends in scenarios ' $A$ ' and ' $B$ ', especially in summer period.

\section{Conclusions}

On the basis of this analysis, it is clear that the hidden energy potential in the form of pressures in some aqueducts may be easily underestimated. Designing the water system also for hydroelectric purposes, by increasing the diameters of the pipeline, could bring to significant environmental advantages and economical benefits. During the design of such embedded system is important to assume accurate forecasts related to the costs of the plant and to the value of the benefit for unit energy $\mathrm{b}$ because they could affect remarkably the final values of design variables. The installation of an inverter is convenient for the case study only when the value of the benefit for unit energy $b$ is equal to $0,10 € / \mathrm{kWh}$ because it leads to smaller pipe diameter and higher head variability. The annual return of scenario 'A' $(b=0,21 € / \mathrm{kWh})$ is higher than the triple of scenario 'B' $(\mathrm{b}=0,10 € / \mathrm{kWh})$ because higher values of available head lead to remarkable increase of produced power values, particularly in summer period. Designing mini-hydro plants embedded with pipelines may involve quite more significant economical improvements than designing without considering hydropower production, reducing remarkably annual net costs.

\section{References}

[1] Bathala, C. T. (1985). Power generation from a water supply system. Water Power \& Dam Constr., 37(10), 13-16

[2] Afshar, A., Jemaa, F., Marino, M. (1990). Optimization of hydropower plant integration in water supply system. J. Water Resour. Plann. Manage., 116(5), 665-675

[3] Pezzinga, G., Tosto, G. (2001). Adeguamento energetico di reti di adduzione idrica in pressione. L'Acqua, 1, 27-34 (in Italian)

[4] Fontana, N., Giugni, M., Portolano, D. (2012). Losses reduction and energy production in water-distribution networks. J. Water Resour. Plann. Manage., 138(3), 237-244

[5] Sammartano, V., Aricò, C., Sinagra, M., Tucciarelli, T. (2015) Cross-flow turbine design for energy production and discharge regulation. J. Hydraul. Eng., 141(3), 04014083.

[6] Sinagra, M., Sammartano, V., Aricò, C., Collura, A. (2016). Experimental and numerical analysis of a cross-flow turbine. J. Hydraul. Eng., 142(1), 04015040.

[7] Sinagra, M., Sammartano, V., Morreale, G., Tucciarelli, T. (2017). A new device for pressure control and energy recovery in water distribution networks. Water, 9(5), 309.

[8] Sammartano, V., Filianoti, P., Sinagra, M., Tucciarelli, T., Scelba, G., Morreale, G. (2017). Coupled hydraulic and electronic regulation of cross-flow turbines in hydraulic plants. J. Hydraul. Eng., 143(1), 04016071. 